10. Физическая гимнастика для людей, ведущих «сидячий» образ жизни // URL: https://vuzlit.ru/406009/fizicheskaya_gimnastika_lyudey_veduschih_sidyachiy_obraz_zhizni (дата обращения: 25.01.2020 г.).

11. Психологические особенности здорового образа жизни (ЗОЖ) // URL: https://urok.1sept.ru/articles/628392 (дата обращения: 25.01.2020 г.).

12. Факторы, определяющие здоровый образ жизни // URL: http://volno.baranovichi.edu.by/main.aspx?guid=1811 (дата обращения: 25.01.2020 г.).

13. Питание пожилых людей: основные принципы и правила // URL: https://dom-prestarelyh.ru/blog/pitaniepozhilykh-lyudey/ (дата обращения: 25.04.2020 г.).

\title{
Евтропкова Д.С. \\ Оценка функционального состояния студенток 1 курса по дисциплине «физическая культура и спорт» элективного направления «Фитнес» (опыт ПетрГУ)
}

Петрозаводский государственный университет

(Россия, Петрозаводск)

doi: 10.18411/trnio-11-2021-154

\section{Аннотация}

В 2016-2017 в Петрозаводском Государственном Университете (ПетрГУ) была внедрена система организации учебного процесса по физическому воспитанию по элективным направлениям с учетом требований ФГОС ВО 3+. Предварительное анкетирование студентов 1 курса позволило определиться с предпочтениями обучающихся. Одним из популярных направлений студентами была выбрана элективная дисциплина «Фитнес» [3, с. 140]. В процессе работы по улучшению качества преподавания дисциплины, с использованием нестандартных и новых видов фитнес технологий, использовать данные результаты исследования показателей функциональных проб дыхательной и сердечнососудистой систем для повышения функционального состояния организма студенток. Результатом исследования стал анализ влияния занятий на функциональное состояние организма студенток 1 курса вуза по дисциплине «физическая культура и спорт» элективной дисциплины «Фитнес». Проводится анализ проведенных функциональных проб, занимающихся, осознанно выбранном направлении электива «Фитнес» и посвящена данная статья.

Ключевые слова: ФГОС, учебный процесс, элективное направление, элективная дисциплина, фитнес, физическая культура, физическое воспитание, студенты, функциональные пробы, функциональное состояние, ПетрГУ.

\section{Abstract}

In 2016-2017 in Petrozavodsk State University (PSU) a new organisational system of the educational process of the physical education of the elective courses considering the Federative State Educational requirements "VO 3+" was introduced. Preliminary questionnaire helped to decide upon the preferences of the first-year students. "Fitness" as an elective discipline was chosen as the most popular one. During the process of working on the discipline teaching improvement with the use of new types of fitness technologies, for the development of the first-year students' functional state of the organisms, we are supposed to use the data from the research results: indexes of the functional tests of breathing and heart systems. The analysis of the impact of the physical activities on the organisms of the first-year students of the department of physical training with the elective course "fitness" are the results of the research. This article is devoted to the functional tests analysis of the students, who are aware of studying this course.

Keywords: FSES (federal state education standard), educational process, elective course, fitness, physical training, PSU (Petrozavodsk state university).

Фитнес, как спортивная специализация элективного выбора в ПетрГУ, на протяжении уже 4 лет является одним из наиболее популярных направлений среди девушек. Количество желающих заниматься на данном элективе ежегодно растет и на данный момент (2019/2020 уч год) составляет более 350 человек (17 учебных групп) [1, с. 5]. Занятия фитнесом 
помогают повышению функционального состояния организма и его функциональной подготовленности и работоспособности, в том числе с использованием нестандартных и новых видов фитнес технологий. Функциональная подготовленность - характеризует состояние основных систем жизнеобеспечения организма, их работоспособность. К наиболее информативным величинам, исследование которых представляет наименьшие трудности, относятся частота сердечных сокращений (ЧСС), артериальное давление (АД), частота дыхания (ЧД), время задержки дыхания [2, с. 245]. Функциональное состояние - комплекс показателей, определяющий уровень жизнедеятельности организма, системный ответ организма на физическую нагрузку, в котором отражается степень интеграции и адекватности функций выполняемой работе. При исследовании функционального состояния организма, занимающегося физическими упражнениями, наиболее важны изменения систем кровообращения и дыхания, именно они имеют основное значение о допустимых параметрах физической нагрузки, от них во многом зависит уровень физической работоспособности [2, c. 167].

Цель данного исследования - изучить функциональное состояние обучающихся 1 курса элективного направления «Фитнес», с использованием четырех не сложных, но значимых функциональных проб. Далее использовать результаты исследования в работе по улучшению качества преподавания дисциплины, повышению функционального состояния организма студенток с использованием нестандартных и новых видов фитнес технологий. В этой связи, был проведен анализ функционального состояния студенток 1 курса, выбравших данное элективное направление впервые и отзанимавшихся в группе данного электива в течение одного семестра.

Анализ функционального состояния студенток 1 курса, выбравших элективное направление «Фитнес» был оценен с помощью четырех функциональных проб. Для оценки состояния дыхательной системы и в целях самоконтроля использовались функциональные пробы с задержкой дыхания, такие как проба Генча и проба Штанге. Для оценки функционального состояния сердечно-сосудистой системы были использованы ортостатическая проба и проба с приседаниями.

Мы оценили данные среди студенток 1курса, занимающихся на элективном направлении «Фитнес». В исследовании функционального состояния приняли участие 20 девушек одной группы данного элективного направления 1 курса ПетрГУ. Студенты 1 курса выбрали данный электив впервые и занимались ровно один семестр.

Проба Генча основана на произвольной задержке дыхания на выдохе, проводится в положении сидя. Предварительно выполняя глубокие: вдох, выдох, вдох. Затем следует спокойный выдох и задержка дыхания с зажатым пальцами носом. Результат - 25-30 сек. норма. Если время задержки дыхания на выдохе меньше 25 сек., то функциональные возможности дыхательной системы низкие.

Проба Генча показала следующие результаты: 12 человек из 20 имеют результат «норма», что составляет $60 \%$ от общего числа тестируемых, 8 человек - это $40 \%$ выше нормы, и ни одного человека нет с низким показателем (рисунок 1).

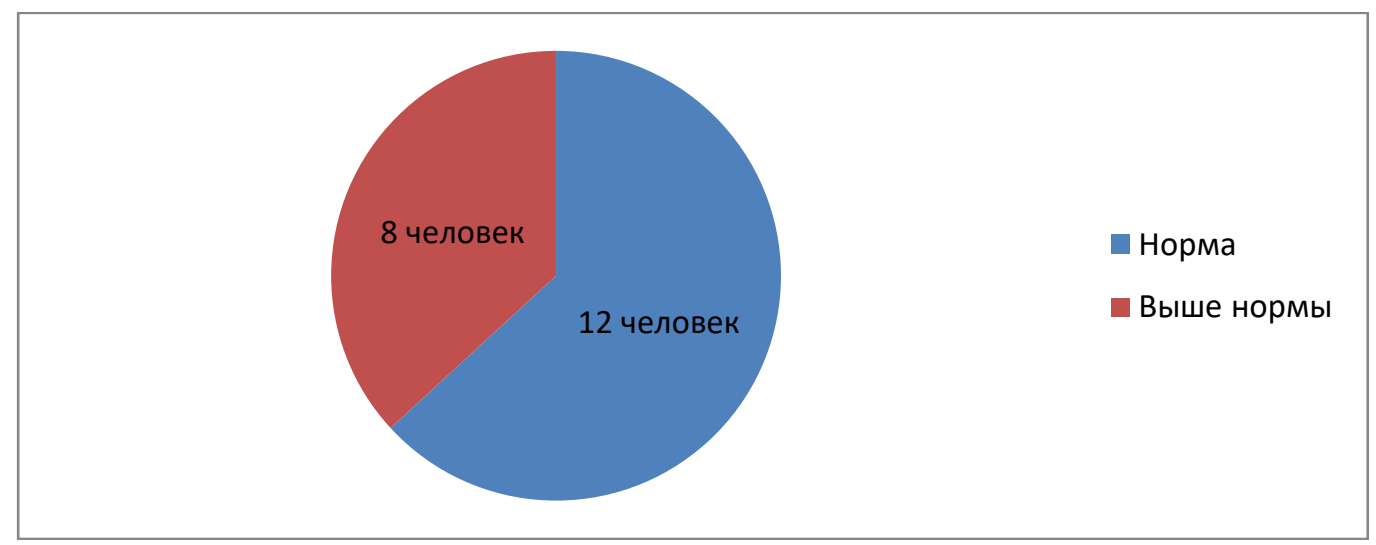

Рисунок 1. Результаты пробы Генча 
Проба Штанге осуществляется с задержкой дыхания на вдохе. Дыхание задерживается на полном вдохе, который выполняется после трех вдохов-выдохов на $3 / 4$ глубины полного вдоха. Результат - 45-55 сек.- норма. Если время задержки дыхания на вдохе меньше 45 сек., то функциональные возможности дыхательной системы низкие.

Так выполнив, пробу Штанге 8 человек из 20 имеют результат «норма», что составляет $40 \%$ от общего числа тестируемых. 9 человек - это 45\% показатель выше нормы и лишь $15 \%$ это 3 человека от общего числа тестируемых показатель ниже нормы (рисунок 2).

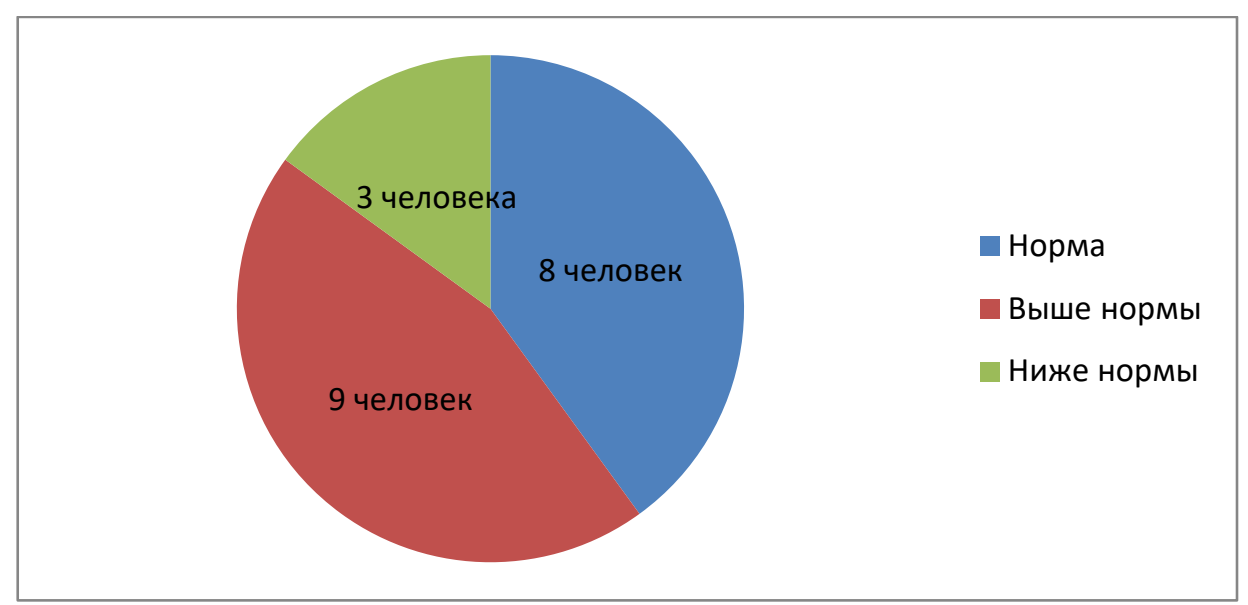

Рисунок 2. Результаты пробы Штанге

Ортостатическая проба позволяет оценить деятельность сердечно-сосудистой системы. Утром, проснувшись, спокойно полежать 2 - 3 минуты, затем измерить частоту сердечных сокращений и встать. Через $1-2$ минуты вновь измерить пульс, теперь в положении стоя. У хорошо тренированного человека разница колеблется в пределах $6-8$ ударов в минуту. Чем выше разница, тем ниже тренированность. Оценка ортостатической пробы: результат ( кол-во уд. в мин.) - менее 10 - отлично, менее 15 - хорошо, менее 20 удовлетворительно , более 20 - неудовлетворительно.

Выполненная ортостатическая проба показала следующие результаты: 10 человек из 20 имеют отличный результат, что составляет $50 \%$ от общего числа тестируемых. 8 человек - это $40 \%$ от общего числа хороший и лишь $10 \%$ - это 2 человека от общего числа удовлетворительный результат. Неудовлетворительные результаты отсутствуют (рисунок 3 ).

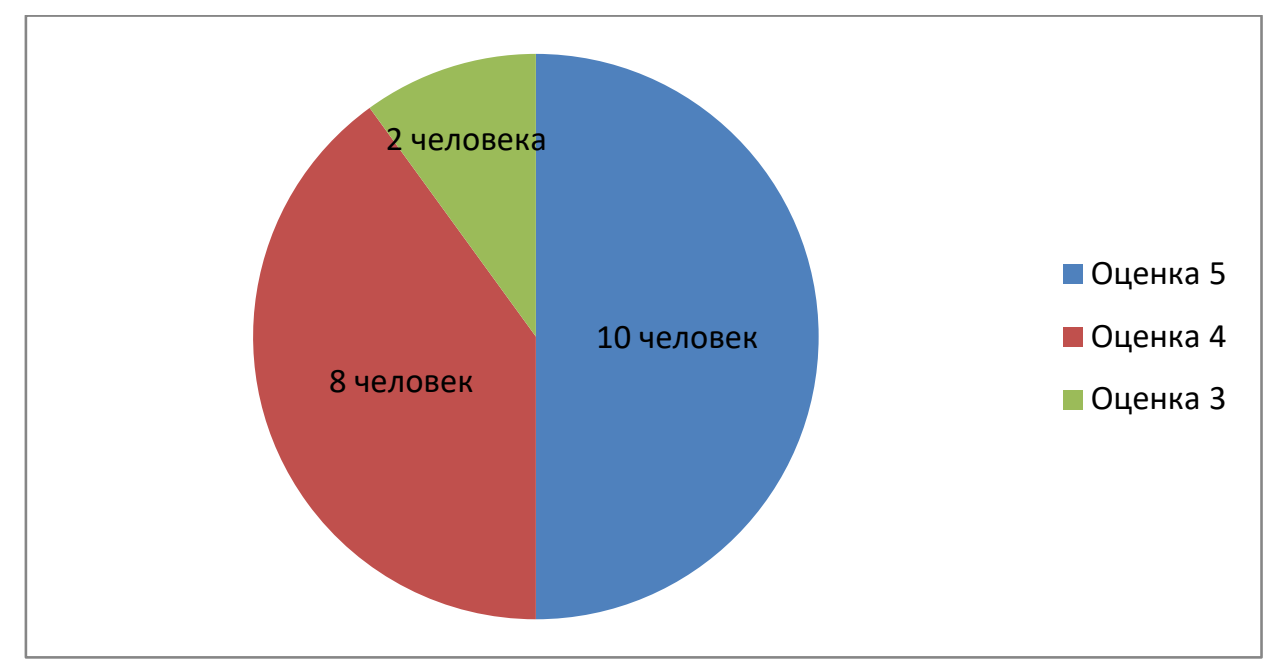

Рисунок 3. Результаты ортостатической пробы

Проба с приседаниями. Оценка функционального состояния сердечно-сосудистой системы: 


\begin{tabular}{|c|c|c|c|c|c|c|}
\hline \multirow{2}{*}{ Tecmbl } & \multirow{2}{*}{ Пол } & \multicolumn{5}{|c|}{ Оценка } \\
\hline & & 5 & 4 & 3 & 2 & 1 \\
\hline \multirow{3}{*}{$\begin{array}{c}\text { ЧСС в покое после } 3 \text { мин. отдыха в положении сидя, } \\
\text { уд./мин. }\end{array}$} & $\mathscr{H}$ & $<71$ & $71-78$ & $79-87$ & $88-94$ & $>94$ \\
\hline & M & $<66$ & $66-73$ & $74-82$ & $83-89$ & $>89$ \\
\hline & ж & & & & & \\
\hline \multirow[t]{3}{*}{20 приседаний за 30 c, \% } & & $<36$ & $36-55$ & $56-75$ & $76-95$ & $>95$ \\
\hline & $M$ & & & & & \\
\hline & $\mathscr{H}$ & & & & & \\
\hline \multirow[t]{2}{*}{ Восстановление пульса после нагрузки, уд./мин. } & & $<2$ & $2-4$ & $5-7$ & $8-10$ & $>10$ \\
\hline & M & & & & & \\
\hline
\end{tabular}

Таким образом, выполнив, пробу с приседаниями 7 человек из 20 имеют отличный результат, что составляет $35 \%$ от общего числа тестируемых, так же результат хорошо имеют $35 \%$ - это 7 человек. 20\% тестируемых имеет удовлетворительный результат, что составляет 4 человека и 10\% - это 2 человека из 20 неудовлетворительный результат (рисунок 4).

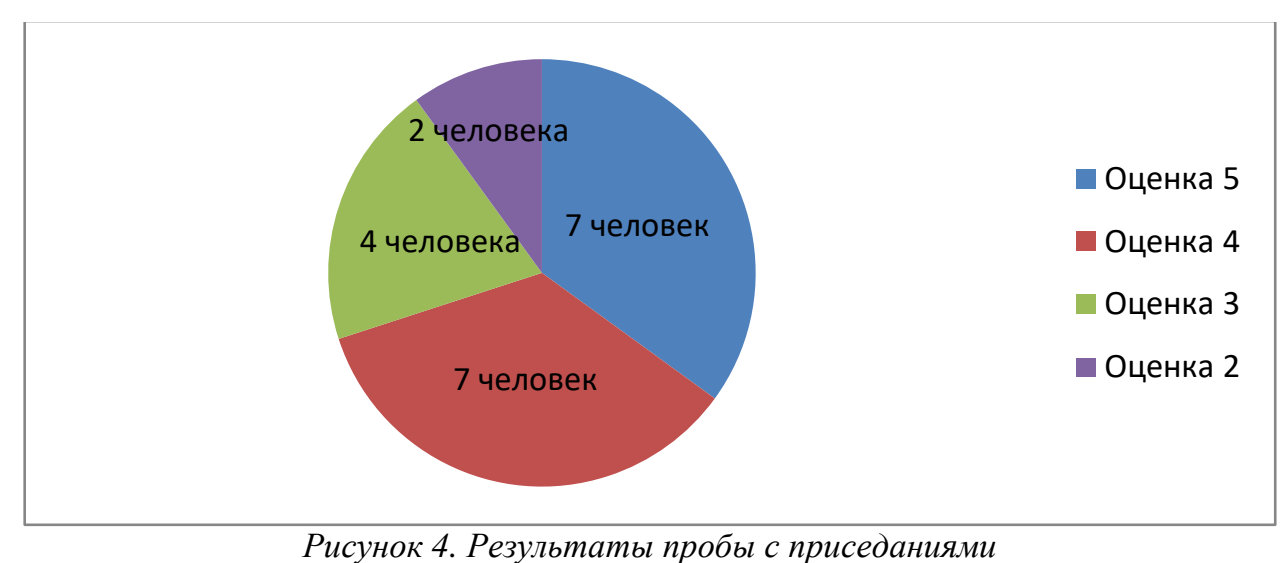

Таким образом, проанализировав все выполненные функциональные пробы можно говорить, что наилучших результатов студентки добились при выполнении проб для оценки состояния дыхательной системы. По высоким значениям пробы Генча, а также, результатам пробы Штанге не сильно отличающиеся от значений по пробы Генча. Это значит, что функциональные возможности дыхательной системы, занимающихся студентов на элективной дисциплине «Фитнес», развита отлично. Что касается оценки функционального состояния сердечно-сосудистой системы, то ситуация такова, что 10 человек имеет отличные результаты по ортостатической пробе, и еще меньше всего 7 человек по пробе с приседаниями имеет отличный результат. В целом состояние сердечно-сосудистой системы хорошее, но ниже показателей оценки дыхательной системы. Это говорит о том, что сердечно-сосудистая система большинства обучающихся по элективу «Фитнес» менее развита, чем дыхательная, что требует коррекции привычного образа жизни обучающегося, подбора как общих, так и индивидуальных дополнительных комплексов по элективному направлению «Фитнес», в том числе с использование нестандартных и новых видов фитнес технологий.

$$
* * *
$$

1. Использование нестандартного оборудования на занятиях по фитнессу// учебно-метод. электронное пособие для обучающихся по всем направлениям подготовки [Электронный ресурс] / Д.С. Евтропкова, А.С. Кариаули. - Петрозаводск: ПетрГУ, 2020-43 с.

2. Ланда, Б.Х. Методика комплексной оценки физического развития и физической подготовленности : учеб. пособие / Б.Х. Ланда. - М. : Советский спорт, 2011. - 348 с.

3. Переход на элективную физическую культуру по направлению «Фитнес», опыт ПетрГУ, Соловьева Н. В., Евтропкова Д. С. В сборнике: Инновационные технологии в науке и образовании. Сборник статей VI Международной научно-практической конференции : в 2 частях. 2017. С. 140-142. 